\title{
PENGELOLAAN LINGKUNGAN HIDUP DALAM PERSPEKTIF ISLAM
}

\author{
Oleb: MS. Ka'ban*
}

\section{Abstract}

The majority of environment damages are caused by of buman actions. Those damages impact to several of natural disasters in the earth like flood, landslide, pollution etc. Actually there were various efforts which have strived to bandle environment damages especially by science and technology approach, but as we know those damages don't stop yet. Based on those facts we need new solution by other approach like appraach and participation of religion to bandle those problems. Because religion bas force relation with the nature and environment. Besides it can convince the people that there is transcendental force of God.

\section{ans}

يكن إرجاع أغلب أشكال فساد البيئة، كالفيضانات، الانكيارات الأرضية، الجفاف، تلوث البيئة وغيرها، إلى العامل البشري. وفي المقابل يقوم البشر كحاولات عليادة لإصلاح البيئة عبر اقترابات علمية وتكنولوجية مختلفة. ورغم. هنا يلاحظ أن معللات فساد البيئة في ازدياد، وأزمتها ترتفع حدة. من أجل هذا تتضح الحلاجة إلى اقتراب آخر أكثر استجابة للأزمة البيئة اللحالية؛ إنه الاقتراب اللديني الذي تقترحه الورقة الحلالية. يتضح عنصر الاستجابة العالية في الاقتراب الديني من خحلال احتوائه على اللعوة لإنشاء عالاقة قوية بين الإنسان وبئته من جهة، ومن جهة أخرى تصوره للكون المستند إلى وجود قوة متعالية . هي المالق عز وجل.

Keywords: terorisme, bukum dan jïhad

* Penulis adalah Menteri Kehutanan Republik Indonesia pada Kabinet Indonesia Bersatu 


\section{A. Pendabuluan}

Permasalahan lingkungan yang kini dihadapi umat manusia umumnya disebabkan oleh dua hal. Pertama, karena kejadian alam sebagai peristiwa yang harus terjadi sebagai sebuah proses dinamika alam itu sendiri. Kedua, sebagai akibat dari perbuatan manusia. Kedua bentuk kejadian di atas mengakibatkan ketidakseimbangan pada ekosistem dan ketidaknyamanan kehidupan makhluk hidup baik manusia, flora maupun fauna. Ketidakseimbangan dan ketidaknyamanan tersebut dapat dikatakan sebagai bencana. Ali Yafie menyebutnya sebagai kerusakan lingkungan hidup. Bentuk-bentuk kerusakan lingkungan itu berupa pencemaran air, pencemaran tanah, krisis keanekaragaman hayati (biological diversity), ketusakan hutan, kekeringan dan krisis air bersih, pertambangan dan kerusakan lingkungan, pencemaran udara, banjir lumpur dan sebagainya. ${ }^{1}$

Kerusakan hutan sebagai salah satu bentuk kerusakan lingkungan hidup adalah ketidakseimbangan yang terjadi dalam ekosistem hutan. Terdapat dua jenis kerusakan hutan yang mungkin terjadi, yaitu gangguan alam dan akibat dari perbuatan tangan manusia. Gangguan alam di antaranya longsot, hama dan penyakit, gempa bumi, kebakaran, dan gelombang pasang air laut. Adapun gangguan akibat ulah manusia ialah jenis gangguan yang disebabkan oleh aktivitas manusia, yaitu kebakaran yang disengaja atau karena kelalaian, penebangan, perladangan, pemukiman, industri, pencemaran dan lain-lain.

Dewasa ini kondisi hutan nasional telah menjadi keprihatinan banyak pihak, baik di dalam negeri maupun masyarakat internasional. Kawasan hutan negara seluas 120,35 juta hektar atau $62,6 \%$ dari luas daratan Indonesia pada saat ini telah mengalami kerusakan yang serius. Pada saat ini hutan yang mengalami degradasi fungsi telah mencapai 59,2 juta hektar. Sungguh fakta yang memprihatinkan. Kerusakan hutan ini disebabkan antara lain oleh pengelolaan hutan yang tidak bijaksana, pembukaan kawasan hutan dalam skala besar untuk berbagai keperluan pembangunan, illegal loging, perambahan hutan, dan kebakaran.

Akibat dari kerusakan hutan ini adalah semakin rentannya wilayah Indonesia dari bencana banjir, tanah longsor dan kekeringan. Di samping itu, Indonesia juga akan kehilangan keanekaragaman hayati (biological diversity) seperti spesies mamalia, reptil, ampibi, burung, ikan, dan lain-lain. Makhluk hidup di bumi akan kekurangan oksigen karena kerusakan hutan yang merupakan paru-paru dunia. Kehidupan di dunia ini akan terganggu karena hutan Indonesia hanya sedikit dapat menyerap karbon yang berbahaya bagi makhluk hidup. Akibat dari kerusakan hutan itu dirasakan paling berat oleh penduduk yang bermatapencaharian langsung dari hutan yaitu sekitar 6 juta orang dan sebanyak 3,4 juta di antaranya bekerja di sektor swasta

${ }^{1}$ Ali Yafie (2006), Merintis Figih Lingkungan Hidup, Jakarta: UFUK Press. p.66. 
kehutanan. Apabila diasumsikan bahwa setiap tenaga kerja sektor kehutanan menanggung minimal 3 orang, maka usaha sektor kehutanan telah menjadi gantungan hidup 24 juta orang. Belum termasuk penyerapan tenaga musiman, yang terserap pada program Gerakan Nasional Rehabilitsi Hutan dan Lahan (GERHAN) yang setiap tahunnya mencapai sekitar 23, 9 juta otang.

Dari sekian banyak persoalan kerusakan lingkungan hidup, ternyata peran manusia sangat besar dalam menciptakan kerusakan tersebut dan manusialah yang banyak menanggung akibatnya. Lalu bagaimana Islam memandang peran manusia dalam mengelola lingkungan hidup ini? Inilah yang akan dibahas dalam tulisan ini.

\section{B. Berbagai Upaya Mengatasi. Krisis Lingkungan}

Sebagai upaya mengatasi kondisi sumber daya hutan yang rusak, agar dapat pulih potensi dan fungsinya, maka Departemen Kehutanan telah menetapkan 5 Kebijakan Prioritas Pembangunan Kehutanan yaitu: (1)Pemberantasan pencurian kayu di hutan negara dan perdagangan kayu ilegal, (2) Revitalisasi sektor kehutanan, khususnya industri kehutanan, (3) Rehabilitasi dan konservasi sumber daya hutan, (4) Pemberdayaan ekonomi masyarakat di dalam dan di sekitar kawasan hutan, dan (5) Pemantapan kawasan hutan.

Para pemerhati dan praktisi lingkungan telah lama berupaya mencarikan jalan keluar dari krisis lingkungan yang terjadi. Di antaranya; melalui berbagai kerjasama, perjanjian antarbangsa dan konvensi lingkungan untuk mengarahkan manusia agar tidak merusak lingkungan. Beberapa hasil pertemuan dan konvensi itu antara lain; Pertemuan Bumi di Rio De Jenerio pada tahun 1992 yang menghasilkan Deklarasi Bumi tahun 1992, Konvensi Bassel mengatur tentang lalu lintas dan sanksi mengenai limbah beracun dan berbahaya, Konvensi CITES mengatur perdagangan spesies flora dan fauna, Konvensi Keanekaragaman Hayati (The Convention on Biological Diversity), dan Konvensi PBB untuk Penanggulangan Perubahan Iklim (United Nation Framework Convention on Climate Change).

Pendekatan ilmu pengetahuan dan teknologi memang diperlukan, akan tetapi itu saja tidak cukup. Masih diperlukan agama untuk terlibat dalam upaya keluar dari krisis lingkungan. Mary Evelyn Tucker, seorang Guru Besar agama dari Bucknel University, mengatakan bahwa agama mempunyai lima resep dasar untuk mengurangi kerusakan hutan dengan cara yang lunak yaitu melalui pendekatan relijius.-Resep agama dalam penyelamatan lingkungan itu adalah; Pertama, reference, yaitu keyakinan yang dimiliki oleh para penganut agama yang dapat diperoleh dari teks kitab suci dan kepercayaannya. Kedua, respect, berupa nilai-nilai yang ditanamkan kepada pemeluknya untuk menghargai sesama makhluk hidup. Ketiga, restrain, agama mengajarkan kepada pemeluknya untuk mampu mengelola dan mengontrol sesuatu supaya penggunaannya tidak mubadzir. Kemmpat, redistribution, agama mengajarkan 
kepada umatnya untuk mengembangkan kesalehan sosial berupa kemampuan untuk menyebarkan kekayaan; kegembiraan dan kebersamaan melalui langkah kedermawanan kepada sesama makhluk Tuhan. Kelima, responsibility, agama mengajarkan bahwa hidup di dunia ini ada tanggung jawab kepada pencipta dan tanggung jawab dalam merawat kondisi lingkungan. ${ }^{2}$

\section{Pandangan Islam tentang Pengelolaan Lingkungan Hidup}

Dalam pandangan Islam, manusia adalah makhluk terbaik di antara semua ciptaan Tuhan ${ }^{3}$ dan berani memegang tanggung jawab mengelola bumi ${ }^{4}$ maka semua yang ada di bumi diserahkan untuk manusia. ${ }^{5}$ Oleh karena itu manusia diangkat menjadi khalifah di muka bumi ${ }^{6}$. Sebagai makhluk terbaik, manusia diberikan beberapa kelebihan di antara makhluk ciptan-Nya, yaitu kemuliaan, diberikan fasialitas di daratan maupun di lautan, mendapat tizki dati yang baik-baik, dan kelebihan yang sempurna dibandingkan makhluk lainnya ${ }^{7}$, serta diberikan kekuasaan dan kelebihan atas makhluk lainnya ${ }^{8}$.

Bumi dan semua isi yang berada di dalamnya diciptakan oleh Allah untuk manusia ${ }^{9}$, segala yang manusia inginkan berupa apa saja yang ada di langit dan bumi, daratan dan lautan serta sungai-sungai, matahari dan bulan, malam dan siang ${ }^{\mathbf{1 0}}$, tanaman dan buah-buahan ${ }^{11}$, binatang melata dan binatang ternak ${ }^{12}$.

Sebagai khalifah di muka bumi, manusia diperintahkan beribadah kepada$\mathrm{Nya}^{13}$ dan diperintah berbuat kebajikan dan dilarang berbuat kerusakan ${ }^{14}$. Selain konsep berbuat kabajikan terhadap lingkungan yang disajikan Al-Quran seperti yang dipaparkan di atas, Rasulullah SAW memberikan teladan untuk mempraktekkannya dalam kehidupan sehari-hari. Hal ini dapat diperhatikan dari Hadist-Hadist Nabi, seperti Hadist tentang pujian Allah kepada orang yang menyingkirkan duri dari jalan; dan bahkan Allah akan mengampuni dosanya, menyingkirkan gangguan dari jalan

${ }^{2}$ Fachruddin Mangun Wijaya (2005), "Agama Mengatasi Krisis Lingkungan", dalam Majalab Tropika. Vol. 9, No. 3-4, Juli-Desember, pp. 8-9.

${ }^{3}$ QS. al-Tien: 4, QS al-Isra'; 70.

${ }^{4}$ QS. al-Ahzab: 72.

${ }^{5}$ QS. al-Baqarah: 29; QS. Ibrahim: 23- 34.

${ }^{6}$ QS. al-Baqarah: 30; QS al-An'am: 165.

${ }^{7} \mathrm{QS}$. al-Isra'; 70.

${ }^{8}$ QS. al-An'am: 165.

${ }^{9}$ QS. al-Baqarah: 29.

${ }^{10} \mathrm{QS}$. Ibrahim: 23- 34.

i QS. al-An'am 141- 142.

${ }^{12}$ QS. Fathir: 27- 28.

${ }^{13}$ QS. al-Dzariyat: 56.

${ }^{14}$ QS. al-Rum: 41; QS. al-Qashash: 77. 
adalah sedekah, menyingkirkan gangguan dari jalan adalah sebagian dari iman, dan - menyingkirkan gangguan dari jalan adalah perbuatan baik.

Di samping itu, Rasulullah melarang merusak lingkungan, mulai dari perbuatan yang sangat kecil dan remeh seperti melarang membuang kotoran (manusia) di bawah pohon yang sedang berbuah dan di aliran sungai, melarang membuang kotoran (manusia) di tengah jalan atau di tempat orang berteduh. Rasulullah juga sangat peduli terhadap kelestarian satwa, sebagaimana diceritakan dalam Hadits riwayat Abu Daud. Rasulullah pernah menegur salah seorang sahabatnya yang pada saat perjalanan, mereka mengambil anak burung yang berada di sarangnya. Karena anaknya dibawa oleh salah seorang dari rombongan Rasulullah tersebut, maka sang induk terpaksa mengikuti terus kemana rombogan itu berjalan. Melihat yang demikian, Rasulullah lalu menegur sahabatnya tersebut dengan mengatakan "siapakah yang telah menyusahkan induk burung ini dan mengambil anaknya? kembalikan anakanak burung tersebut kepada induknya!".

\section{Kewajiban Umat Islam dan Upaya Pemerintah dalam Pelestarian Lingkungan Hidup}

Dalam berinteraksi dan mengelola alam serta lingkungan hidup itu, manusia mengemban tiga amanat dari Allah. Pertama, al-intifa'. Allah mempersilahkan kepada umat manusia untuk mengambil manfaat dan mendayagunakan hasil alam dengan sebaik-baiknya demi kemakmuran dan kemaslahatan. Kedua, al-itibar. Manusia dituntut untuk senantiasa memikirkan dan menggali rahasia di balik ciptaan Allah seraya dapat mengambil pelajaran dari berbagai kejadian dan peristiwa alam. Ketiga, al-islah. Manusia diwajibkan untuk terus menjaga dan memelihara kelestarian lingkungan itu.

Dengan semangat mengemban dan melaksanakan amanat di atas, yaitu menjaga, memelihara dan memanfaatkan sumber daya alam yang ada di alam semesta ini, termasuk sumber daya hutan, Departemen Kehutanan mencoba dan betusaha merangkul semua pihak untuk berperan secara bersama-sama dalam pembangunan kehutanan. Kegiatan ini dapat berupa social forestry, hutan kemasyarakatan, Pengelolaan Hutan Bersama Masyarakat, Hutan rakyat, dan manajemen Kolaboratif di Hutan Konservasi, GERHAN, Kecil Menanam Dewasa Memanen (KMDM), dan lain-lain yang berupaya memberikan peran sebesar-besarnya kepada masyarakat.

Peran serta masyarakat dalam kegiatan penanaman untuk penghijauan dan perbaikan lingkungan hidup searah dengan tujuan Gerakan Rehabilitasi Hutan dan Lahan (GERHAN). Gerakan ini diharapkan mendapat dukungan dari seluruh lapisan masyarakat, mulai dari kelompok masyarakat yang termuda, hingga orang dewasa serta kaum tua. Untuk menarik minat serta menumbuhkan budaya menanam sejak usia dini, Departemen Kehutanan telah mencanangkan kegiatan Kecil Menanam Dewasa Memanen (KMDM) dalam rangka mendukung Gerakan Nasional 
Rehabilitasi Hutan dan Lahan (GERHAN) itu. Kegiatan ini akan melibatkan anakanak usia sekolah dari SD dan Madrasah Ibtidaiyah di seluruh Indonesia. Kegiatan ini juga telah mendapat dukungan dari lembaga-lembaga pendidikan tingkat dasar hingga perguruan tinggi.

Sebagai bagian dari proses pendidikan serta dalam rangka mensukseskan GERHAN dan KMDM itu telah dan akan terus dilakukan penghijauan dengan penanaman pohon di lingkungan Pondok Pesantren, baik yang ada di pulau Jawa maupun di daerah lainnya di Indonesia. Departemen Kehutanan berupaya merangkul berbagai pihak untuk terus melakukan rehabilitas dan konservasi hutan dan lahan. Kesepakatan kerjasama penanaman telah dilakukan dengan berbagai lembaga pendidikan, pesantren dan organisasi sosial, di antaranya dengan Pondok Pesantren Tebu Ireng, Gontor, Pengurus As Syafi'iyyah, PBNU, PP Muhammadiyah, PERSIS, PSII, BKPRMI, dan organisasi sosial kemasyarakatan lainnya.

\section{DAFTAR PUSTAKA}

Ahsin Sakho Muhammad, et. Al. (2004), Fiqib Lingkungan (Fiqh al-Bi'ab), Jakarta: INFORM.

Ali Yafie et. al. (1997), Islam dan Lingkungan Hidup, Jakarta: Yayasan Swarna Bhumy. (2006), Merintis Fiqih Lingkungan Hidup, Jakarta: UFUK Press.

Departemen Kehutanan (1999), Pembangunan Hutan Berkelanjutan Cerminan Iman dan Taqwa, Jakarta: Departemen Kehutanan dan Perkebunan.

Fachruddin Mangun Wijaya (2005), “Agama Mengatasi Krisis Lingkungan”, dalam Majalab Tropika. Vol. 9, No. 3 - 4, Juli - Desember.

Ngadiono (2004), 35 Tabun Pengelolaan Hutan-Indonesia Refleksi dan Prospek, Bogor:

Yayasan Adi Sanggoto. 